\title{
Refractory Sclerosing Mesenteritis Involving the Small Intestinal Mesentery: A Case Report and Literature Review
}

\author{
Katsuya Endo ${ }^{1}$, Rintaro Moroi ${ }^{1}$, Mikako Sugimura ${ }^{2}$, Fumiyoshi Fujishima ${ }^{3}$, Takeshi Naitoh ${ }^{4}$, \\ Naoki Tanaka ${ }^{4}$, Hisashi Shiga ${ }^{1}$, Yoichi Kakuta ${ }^{1}$, Seiichi Takahashi ${ }^{1}$, \\ Yoshitaka Kinouchi ${ }^{1}$ and Tooru Shimosegawa ${ }^{1}$
}

\begin{abstract}
A 28-year-old Japanese man presented with upper abdominal pain. Computed tomography (CT) revealed a soft tissue mass in the small bowel mesentery. We diagnosed the patient with sclerosing mesenteritis according to the histological findings of small bowel mesentery. Although he was treated with prednisolone, colchicine and azathioprine, neither his symptoms nor CT findings improved. This case is rare in that the disease was refractory. The characteristics of Japanese patients with sclerosing mesenteritis involving small bowel mesentery are not well understood. We herein describe the details of such patients based on a literature review including 32 recently reported Japanese cases.
\end{abstract}

Key words: sclerosing mesenteritis, mesenteric panniculitis, small bowel, Japanese

(Intern Med 53: 1419-1427, 2014)

(DOI: 10.2169/internalmedicine.53.1813)

\section{Introduction}

Sclerosing mesenteritis is a rare idiopathic disorder that affects the adipose tissue of the mesentery with varying degrees of fat necrosis, inflammation and fibrosis (1). Although the natural history of this disease is not well understood, many patients exhibit a good response to treatment and with a good prognosis. The disease usually involves the small bowel mesentery in Western patients (2), in contrast to the large bowel mesentery in Japanese patients $(3,4)$. In particular, the sigmoid mesentery is most frequently involved among the large bowel mesentery in Japanese patients $(3,4)$. Therefore, the major portion of the mesentery involved in sclerosing mesenteritis appears to differ between races. However, the reasons for this difference have not been clarified. The characteristics of Japanese patients with sclerosing mesenteritis involving the small bowel mesentery are also not well understood.

In this report, we present a rare Japanese case of refractory sclerosing mesenteritis involving the small bowel mesentery. We describe the details of our patient and provide a literature review including recent Japanese case reports in order to compare the various presentations, etiologies, diagnoses and treatments for sclerosing mesenteritis.

\section{Case Report}

A 28-year-old Japanese man was admitted to our hospital with a three-month history of upper abdominal pain. The upper abdominal pain had been increasing gradually since onset, and severe pain persisted throughout almost the entire day of admission. The patient exhibited no changes in bowel habits or body weight loss. He had no past history of any diseases, including abdominal surgery or trauma, and no history of medication use. He also had no history of smoking

\footnotetext{
${ }^{1}$ Division of Gastroenterology, Tohoku University Graduate School of Medicine, Japan, ${ }^{2}$ Department of Gastroenterology, NHO Sendai Medical Center, Japan, ${ }^{3}$ Department of Pathology, Tohoku University Graduate School of Medicine, Japan and ${ }^{4}$ Division of Gastrointestinal Surgery, Department of Surgery, Tohoku University Hospital, Japan

Received for publication September 25, 2013; Accepted for publication January 8, 2014

Correspondence to Dr. Katsuya Endo, kendo@med.tohoku.ac.jp
} 
Table 1. Laboratory Data on the Admission

\begin{tabular}{lclclc}
\hline WBC & $7,300 / \mu \mathrm{L}$ & AST & $22 \mathrm{IU} / \mathrm{L}$ & PT & $105.1 \%$ \\
Seg & $81 \%$ & ALT & $30 \mathrm{IU} / \mathrm{L}$ & APTT & $26.6 \mathrm{sec}$ \\
Eosino & $1 \%$ & ALP & $198 \mathrm{IU} / \mathrm{L}$ & & \\
Baso & $0 \%$ & TP & $5.4 \mathrm{~g} / \mathrm{dL}$ & IgG & $378 \mathrm{mg} / \mathrm{dL}$ \\
Lymph & $9 \%$ & Alb & $3.4 \mathrm{~g} / \mathrm{dL}$ & $\mathrm{IgA}$ & $153 \mathrm{mg} / \mathrm{dL}$ \\
Mono & $9 \%$ & $\mathrm{BUN}$ & $11 \mathrm{mg} / \mathrm{dL}$ & $\mathrm{IgM}$ & $109 \mathrm{mg} / \mathrm{dL}$ \\
$\mathrm{RBC}$ & $491 \times 104 / \mu \mathrm{L}$ & $\mathrm{Cr}$ & $0.9 \mathrm{mg} / \mathrm{dL}$ & $\mathrm{IgG} 4$ & $6.5 \mathrm{mg} / \mathrm{dL}$ \\
$\mathrm{Hb}$ & $15.8 \mathrm{~g} / \mathrm{dL}$ & $\mathrm{Na}$ & $142 \mathrm{mEq} / \mathrm{L}$ & $\mathrm{IgE}$ & $85.2 \mathrm{IU} / \mathrm{mL}$ \\
$\mathrm{Ht}$ & $45.4 \%$ & $\mathrm{~K}$ & $3.7 \mathrm{mEq} / \mathrm{L}$ & $\mathrm{sIL}-2 \mathrm{R}$ & $177 \mathrm{U} / \mathrm{mL}$ \\
$\mathrm{Plt}$ & $26.4 \times 104 / \mu \mathrm{L}$ & $\mathrm{Cl}$ & $105 \mathrm{mEq} / \mathrm{L}$ & ANA & negative \\
& & $\mathrm{CRP}$ & $0.1 \mathrm{mg} / \mathrm{dL}$ & & \\
\hline
\end{tabular}

WBC: white bold cell, Seg: segmented neutrophils, Eosino: eosinophils, Baso: basophil, Lymph: lymphocytes, Mono: monocytes, RBC: red blood cell, $\mathrm{Hb}$ : hemoglobin, $\mathrm{Ht}$ : hematocrit, Plt: platelets, AST: aspartate aminotransferese, ALT: alanine aminotransferase, ALP: alkaline phosphatase, TP: total protein, Alb: albumin, BUN: blood urea nitrogen, Cr: creatinine, Na: sodium, $\mathrm{K}$ : potassium, $\mathrm{Cl}$ : chloride, CRP: C-reactive protein, PT: prothrombin time, APTT: activated partial thromboplastin time, IgG: immunoglobulin G, IgA: immunoglobulin A, IgM: immunoglobulin M, IgE: immunoglobulin E, IgG4: immunoglobulin G4, sIL-2R: soluble interleukin2 receptor, ANA: anti-nuclear antibody

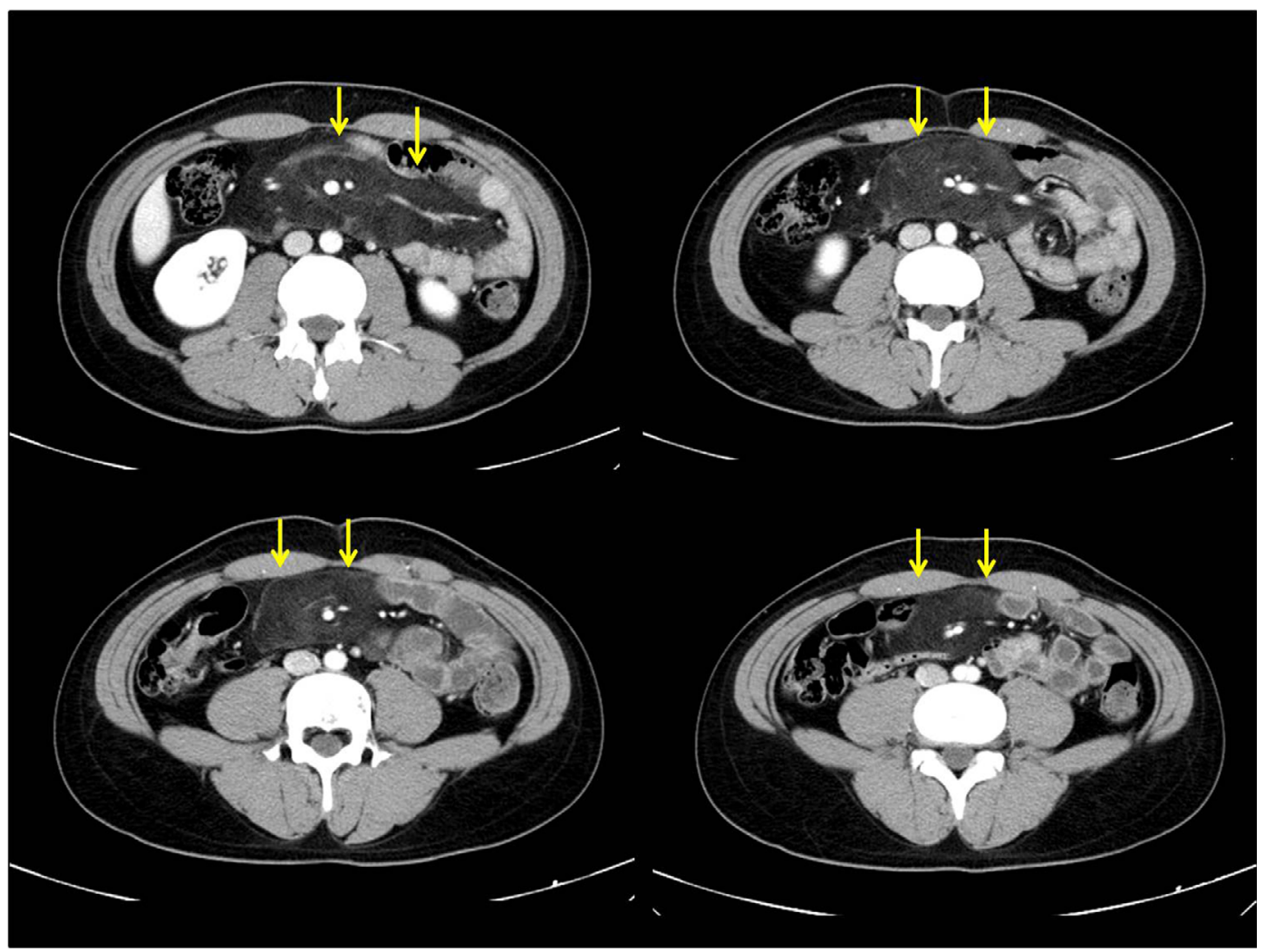

Figure 1. Abdominal dual-phase computed tomography (CT) revealed a soft tissue mass in the small bowel mesentery (arrows).

or drinking and no family history of autoimmune disease or any form of malignancy.

On admission, the patient was $170 \mathrm{~cm}$ tall and weighed $65 \mathrm{~kg}$. His vital signs were stables, with no fever. A physical examination revealed abdominal tenderness, a palpable mass in the upper abdomen and slight pitting edema of the lower extremities.

The laboratory findings (Table 1) indicated low levels of total protein, albumin and IgG. A blood cell count and the C-reactive protein, IgE and IgG4 levels were normal. Antinuclear antigens were negative.
Abdominal dual-phase computed tomography (CT) disclosed a soft tissue mass in the small bowel mesentery (Fig. 1). Abdominal magnetic resonance imaging (MRI) also demonstrated a soft tissue mass in the small bowel mesentery, similar to the CT findings. The image of the pancreas was normal on both CT and MRI. Positron emission tomography (PET) combined with CT was negative. Gastroduodenoscopy and total colonoscopy showed no abnormal findings. Radiography of the small intestine indicated slight edema in the jejunum. Per oral double-balloon enteroscopy (DBE) revealed mucosal edema, white villi, white nodules 


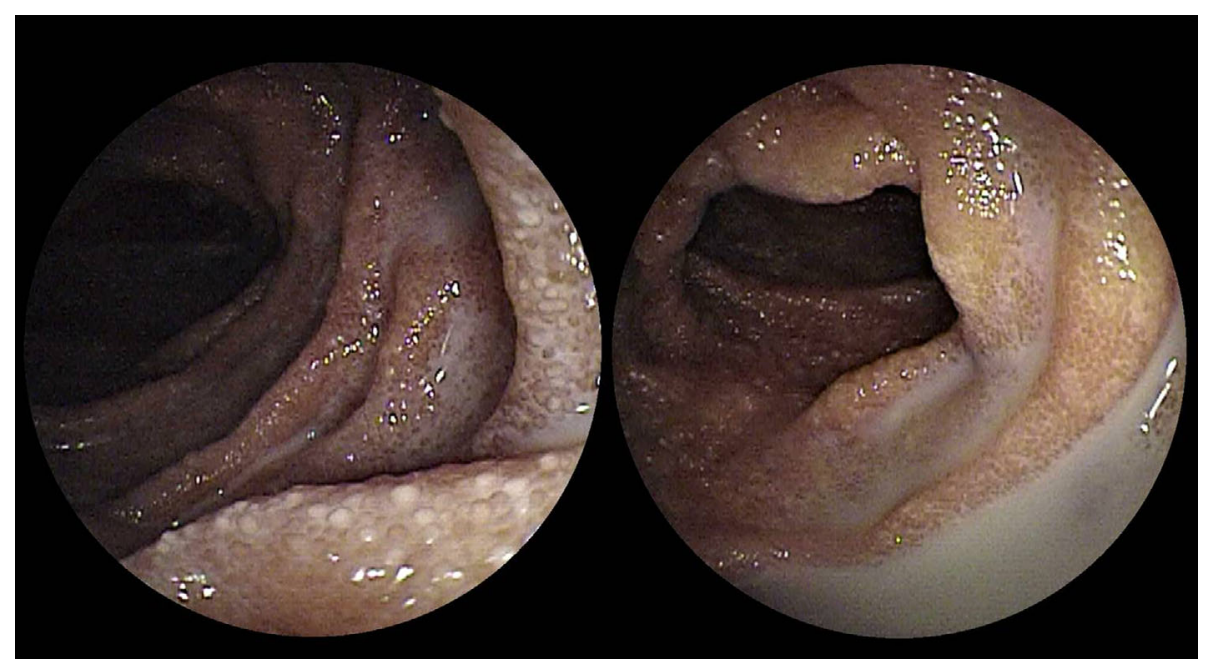

Figure 2. Per oral double-balloon enteroscopy (DBE) showed mucosal edema, white villi, white nodules and white debris in the third portion of the duodenum and jejunum.
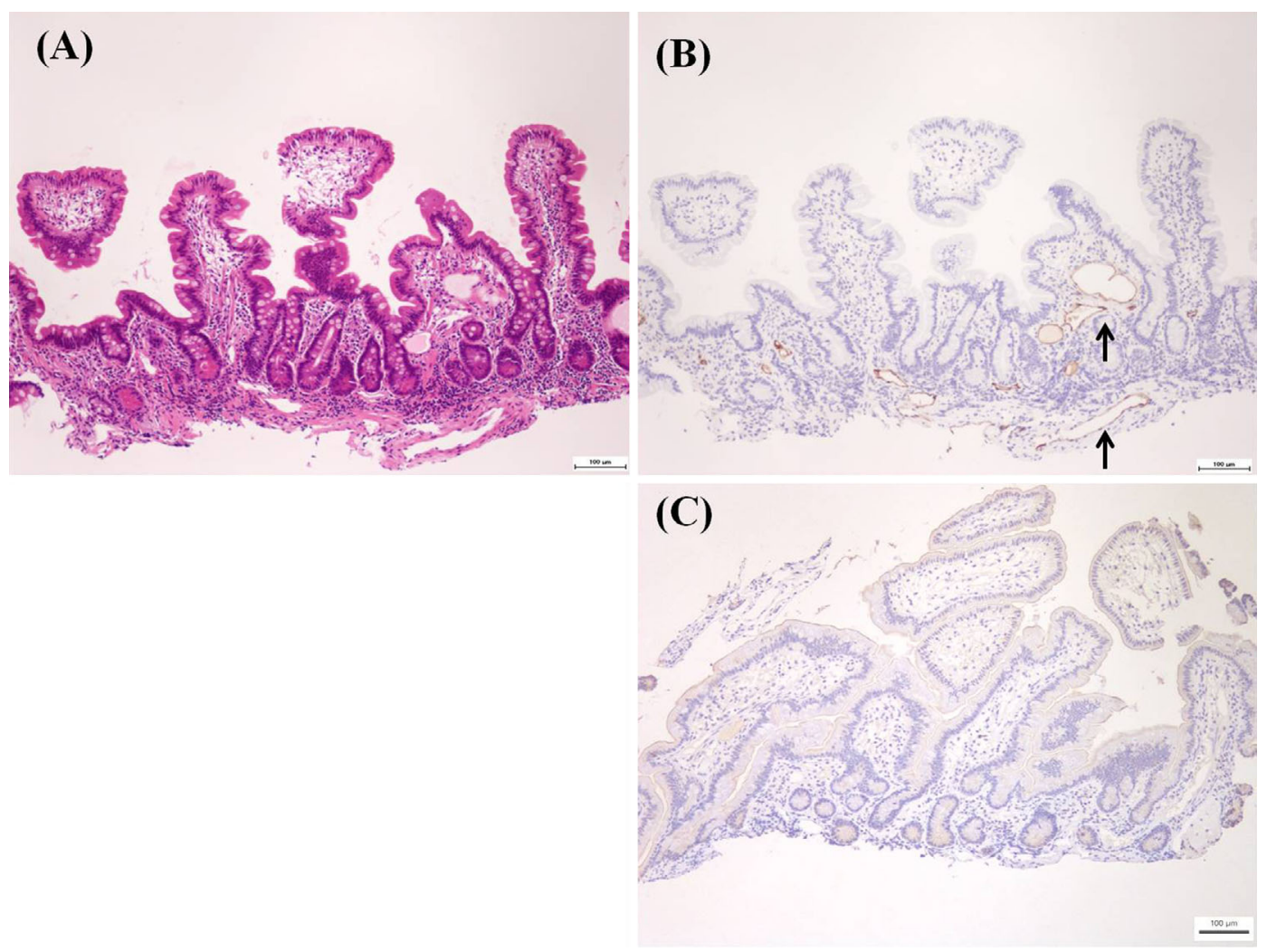

Figure 3. Microscopic findings of the biopsy specimens obtained from the jejunal mucosa revealed infiltration of chronic inflammatory cells and lymphangiectasia (arrows). Immunohistochemically, there were no IgG4-positive cells in the specimens. (A) Hematoxylin and Eosin staining, $\times 10$, (B) Immunohistochemical staining for D2-40, ×10, (C) Immunohistochemical staining for IgG4, ×10

and white debris in the third portion of the duodenum and jejunum (Fig. 2). A histological examination of the biopsy specimens obtained from the jejunal mucosa demonstrated infiltration of chronic inflammatory cells and lymphangiectasia (Fig. 3A, B). Immunohistochemically, there were no IgG4-positive cells in the specimens (Fig. 3C) and no evidence of malignancy, including carcinoma or lymphoma. Based on these findings, a diagnosis of sclerosing mesenteri- tis was highly suspected. In order to obtain pathological confirmation and completely exclude the possibility of malignancy, we performed an open surgical biopsy under general anesthesia. The gross findings of laparotomy included diffuse mesenteric thickening that formed a mass lesion in the jejunal mesentery (Fig. 4A, B). Additionally, the portion of the jejunum affected by the mesenteric mass appeared edematous, and dilated lymphatic vessels were noted on the 


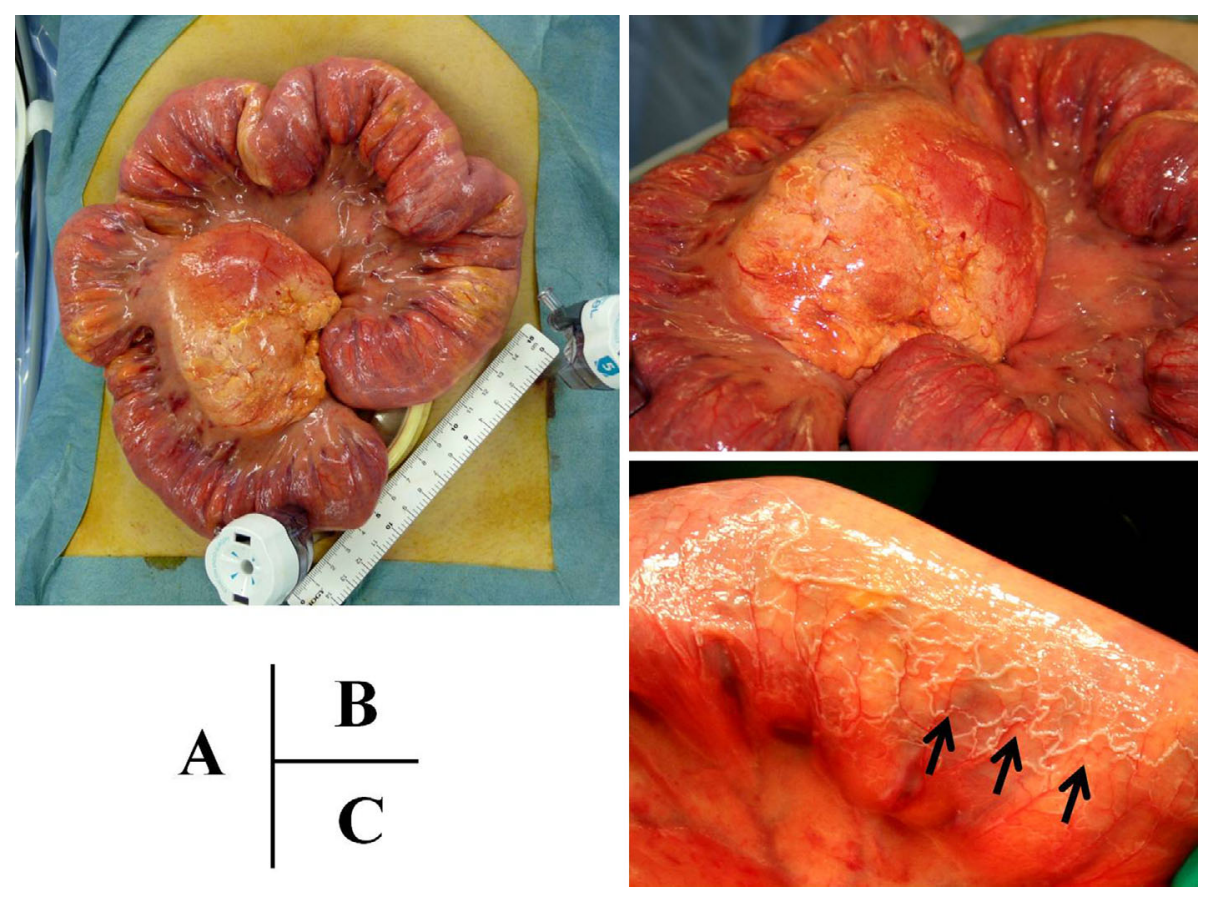

Figure 4. (A) and (B): The gross findings during laparotomy revealed diffuse mesenteric thickening that formed a mass lesion in the mesentery of the oral jejunum. (C): The jejunum around the mesenteric mass appeared edematous. Dilated lymphatic vessels were observed on the surface of the jejunal serosa (arrows).

surface of the jejunal serosa (Fig. 4C). A histological examination of the thickened mesentery revealed fat necrosis with foamy macrophages and infiltration of chronic inflammatory cells (Fig. 5A, B). No apparent fibrosis was observed. Immunohistochemically, there were no IgG4-positive cells in the specimens (Fig. 5C). Therefore, we finally diagnosed the patient with sclerosing mesenteritis.

Treatment with $30 \mathrm{mg}$ of prednisolone once daily was started; however, the patient's symptoms (upper abdominal pain and pretibial edema) did not improve. Therefore, the daily dose of prednisolone was gradually reduced every two weeks. A follow-up CT scan performed four weeks after the first administration of prednisolone revealed that the mass lesion in the mesentery had not changed. Although we additionally administered colchicine and azathioprine, the patient exhibited no response to these treatments. A follow-up CT scan performed approximately 1.5 years after symptom onset demonstrated that the mass lesion in the mesentery remained unchanged. The patient now receives follow-up visits and takes pain-relieving drugs.

\section{Discussion}

Sclerosing mesenteritis is a rare, idiopathic, benign, chronic fibrosing inflammatory disease that affects the adipose tissue of the mesentery $(5,6)$.

Since the disease was first reported in 1924, various cases have been reported in the literature under several terms: retractile mesenteritis, sclerosing mesenteritis, mesenteric panniculitis, mesenteric lipodystrophy and so on. In these re- ports, the patients exhibited various pathological features, including fat necrosis, chronic inflammation and fibrosis. In recent years, these histological variants have been thought to be based on a single pathological entity characterized by nonspecific chronic inflammatory infiltration and fibrosis in mesenteric fat. Adipocyte necrosis (mesenteric lipodystrophy) is thought to progress to a chronic inflammatory state (mesenteric panniculitis) and finally to fibrosis (sclerosing mesenteritis). Therefore, sclerosing mesenteritis may be the best proposed umbrella term $(1,2)$. In the present case, fat necrosis and infiltration of chronic inflammatory cells were observed in the histological findings; however, no apparent fibrosis was detected. Therefore, in the narrow sense, the strict histological diagnosis was mesenteric panniculitis. However, as mentioned above, "sclerosing mesenteritis" is thought be the best diagnosis to represent the patient's condition as an umbrella term.

Most studies from Western countries have indicated that sclerosing mesenteritis is more common in men than women, on the order of 2:1. Most patients are in the fifth to seventh decades of life, with a median age of 65 years (2). Pediatric cases are rare because children have lower amounts of mesenteric fat than adults (7). In Western patients, the disease usually involves the small bowel mesentery. Although some patients with involvement of the sigmoid mesentery have been reported $(1,8-10)$, such cases are very rare. On the other hand, in Japanese patients, the disease often involves the large bowel mesentery $(3,4)$. Mizutani et al. examined 109 Japanese patients and reported that only $36 \%$ had small bowel mesentery involvement, while $58 \%$ 

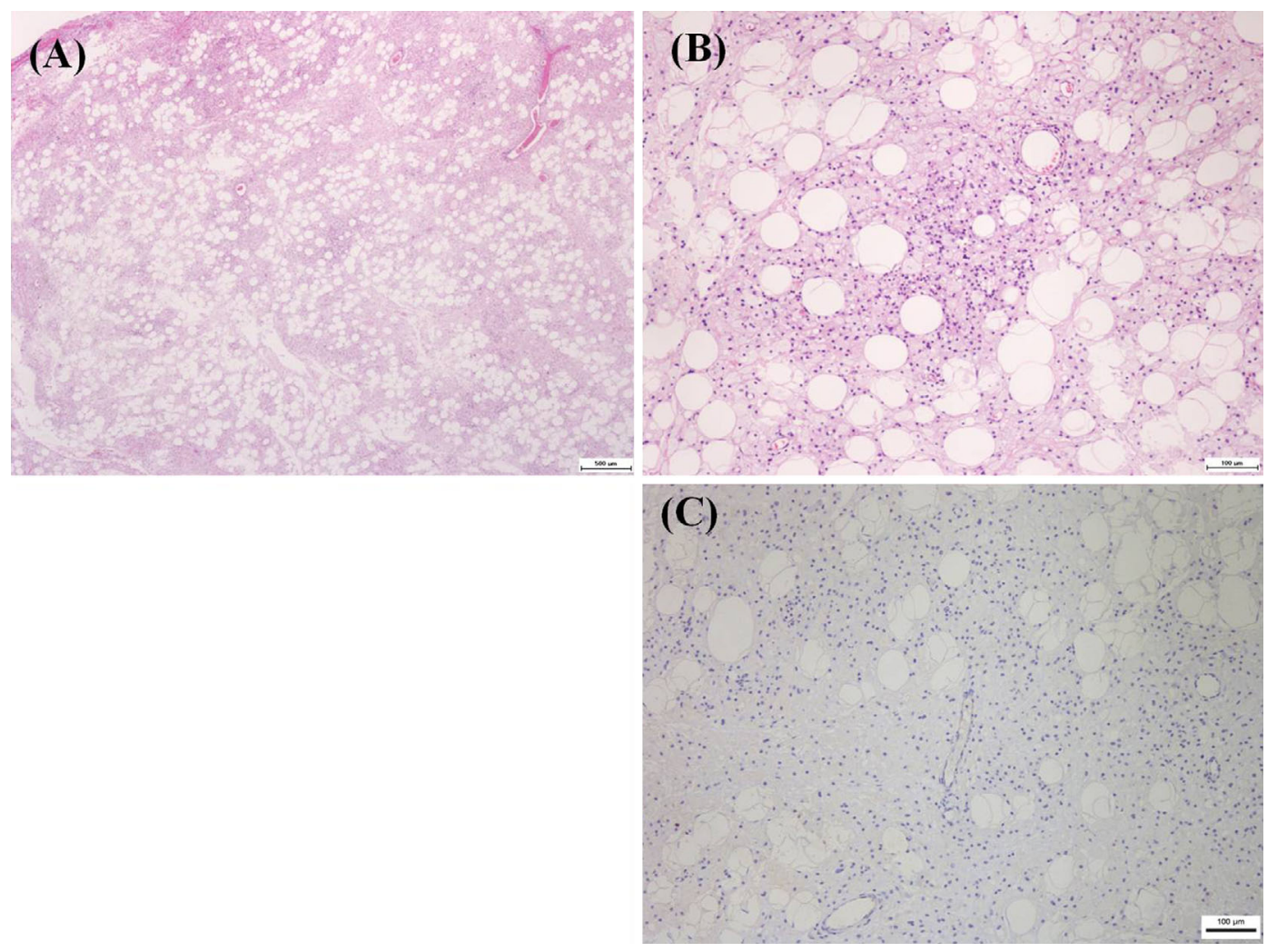

Figure 5. The microscopic findings showed fat necrosis with foamy macrophages (A) and chronic inflammation (B). Immunohistochemically, there were no IgG4-positive cells (C). (A) Hematoxylin and Eosin (H\&E) staining, ×2, (B) H\&E staining, ×10, (C) Immunohistochemical staining for IgG4, $\times \mathbf{1 0}$

had large bowel mesentery involvement (11). The authors also found that the sigmoid mesentery was most frequently involved among the large bowel mesentery (11). Therefore, the portion of the mesentery most frequently involved in sclerosing mesenteritis appears to differ between races. Although some genetic factors may potentially be involved, the precise reasons underlying these differences have not been clarified.

The characteristics of Japanese patients with sclerosing mesenteritis involving the small bowel mesentery are not well understood. In order to elucidate the background factors and clinical courses of such patients, we reviewed recent Japanese cases. We conducted a comprehensive search of MEDLINE ${ }^{\circledR} /$ PubMed $^{\circledR}$ and ICHUSHI ${ }^{\circledR}$ from 2000 to July 2013 using the term "sclerosing mesenteritis" and extracted 32 case reports of Japanese patients with sclerosing mesenteritis involving the small bowel mesentery. The demographic and clinical characteristics of the 33 patients, including the present patient, are summarized in Table 2. The average age at diagnosis was $61 \pm 16.3$ years (mean \pm S.D.), and 25 of the 33 patients $(76 \%)$ were men. Seven patients contracted the disease after abdominal surgery, while four patients also had chylous ascites and one patient also had protein-losing enteropathy (12). Although the evidence was insufficient for verification, our patient was also presumed to have, with a relatively high probability, protein-losing enteropathy, according to the serologic, endoscopic and histo- logical findings. In addition, one patient had IgG4-related sclerosing mesenteritis (13). As for the diagnostic method used in each case, 12 patients were diagnosed using CT scans only, 11 patients were diagnosed using open surgical biopsies and 10 patients were diagnosed based on the pathological findings of the surgically removed involved mesentery. As for treatment, 21 of the 33 cases were managed with medical treatment only (Table 3 ). In the medical treatment group, steroids were administered in 12 of the 21 cases, and only one of these patients (our patient) was resistant to steroid therapy. Twelve of the 33 patients were treated surgically (Table 4). In four of these 12 cases, surgery was performed in order to make a histological diagnosis. In these four cases, it was necessary to rule out the presence of malignant tumors histologically because the involved mesentery formed mass lesions. Three cases underwent surgery due to the presence of ileus, three patients underwent surgery due to resistance to conservative therapy and two patients underwent surgery to control acute symptoms. As for the operative procedures, resection of the small intestine was performed in nine of the 12 surgical interventions; the operation was performed successfully in 11 cases. The clinical courses of the 11 successfully treated patients were good. However, intended resection of the involved lesion was impossible in one case, and the patient was reported to have died after the surgery. Overall, in 30 of the 33 cases $(91 \%)$, the clinical course after medical treatment 
Table 2. Summary of Recent Japanese Cases with Sclerosing Mesenteritis Involving Small Bowel Mesentery

\begin{tabular}{|c|c|c|c|c|c|c|c|}
\hline $\begin{array}{l}\text { Case } \\
\text { No. }\end{array}$ & Year & Reference & Age & Sex & Diagnostic Method & Main Treatment & Other Information \\
\hline 1 & 2000 & {$[41]$} & 48 & $\mathrm{M}$ & open biopsy & gamma globulin & acute onset \\
\hline 2 & 2001 & {$[42]$} & 53 & M & $\mathrm{CT}$ & conservative & \\
\hline 3 & 2001 & & 50 & M & $\mathrm{CT}$ & steroid & post-opereted case \\
\hline 4 & 2002 & {$[43]$} & 63 & M & open biopsy & duodeno-jejunostomy & \\
\hline 5 & 2002 & & 31 & $\mathrm{~F}$ & $\mathrm{CT}$ & conservative & \\
\hline 6 & 2003 & {$[31]$} & 65 & M & $\mathrm{CT}$ & steroid & post-opereted case \\
\hline 7 & 2003 & {$[44]$} & 33 & M & open biopsy & steroid & \\
\hline 8 & 2003 & {$[45]$} & 89 & M & open biopsy & steroid & \\
\hline 9 & 2003 & & 41 & $\mathrm{~F}$ & open biopsy & conservative & \\
\hline 10 & 2003 & {$[11]$} & 73 & M & $\begin{array}{l}\text { resection of the involved } \\
\text { mesentery }\end{array}$ & $\begin{array}{c}\text { partial resection of the small } \\
\text { bowel }\end{array}$ & \\
\hline 11 & 2004 & & 69 & M & $\mathrm{CT}$ & steroid & post-opereted case \\
\hline 12 & 2004 & & 67 & $\mathrm{~F}$ & $\mathrm{CT}$ & conservative & \\
\hline 13 & 2004 & {$[46]$} & 77 & $\mathrm{~F}$ & open biopsy & steroid & accompanied by chylous ascites \\
\hline 14 & 2005 & & 72 & M & open biopsy & $\begin{array}{l}\text { jejunal-transeverse } \\
\text { colostomy, steroid }\end{array}$ & post-opereted case \\
\hline 15 & 2005 & [47] & 74 & $\mathrm{~F}$ & $\mathrm{CT}$ & conservative & \\
\hline 16 & 2006 & & 79 & M & $\mathrm{CT}$ & steroid & \\
\hline 17 & 2006 & & 77 & $\mathrm{~F}$ & $\begin{array}{l}\text { resection of the involved } \\
\text { mesentery }\end{array}$ & $\begin{array}{l}\text { duodeno-jejunostomy, partial } \\
\text { resection of the small bowel }\end{array}$ & post-opereted case \\
\hline 18 & 2006 & {$[3]$} & 37 & M & $\begin{array}{l}\text { resection of the involved } \\
\text { mesentery }\end{array}$ & adhesiotomy & \\
\hline 19 & 2006 & & 62 & M & open biopsy & steroid & accompanied by sarciodosis \\
\hline 20 & 2007 & & 39 & M & open biopsy & gamma globulin & \\
\hline 21 & 2007 & {$[4]$} & 79 & M & $\mathrm{CT}$ & steroid & accompanied by chylous ascites \\
\hline 22 & 2007 & {$[48]$} & 79 & $\mathrm{~F}$ & $\begin{array}{l}\text { resection of the involved } \\
\text { mesentery }\end{array}$ & $\begin{array}{c}\text { partial resection of the small } \\
\text { bowel }\end{array}$ & \\
\hline 23 & 2007 & & 56 & M & $\begin{array}{l}\text { resection of the involved } \\
\text { mesentery }\end{array}$ & ileocecectomy & post-opereted case \\
\hline 24 & 2008 & [49] & 58 & M & $\begin{array}{l}\text { resection of the involved } \\
\text { mesentery }\end{array}$ & $\begin{array}{c}\text { partial resection of the ileum } \\
+ \text { steroid }\end{array}$ & post-opereted case \\
\hline 25 & 2008 & {$[50]$} & 75 & M & $\begin{array}{l}\text { resection of the involved } \\
\text { mesentery }\end{array}$ & partial resection of the ileum & \\
\hline 26 & 2009 & {$[51]$} & 51 & M & $\mathrm{CT}$ & conservative & \\
\hline 27 & 2011 & {$[12]$} & 77 & M & $\mathrm{CT}$ & conservative & $\begin{array}{l}\text { accompanied by protein-losing } \\
\text { enteropahty }\end{array}$ \\
\hline 28 & 2011 & {$[13]$} & 82 & M & $\begin{array}{l}\text { resection of the involved } \\
\text { mesentery }\end{array}$ & ileocecectomy & IgG4-rerated sclerosing mesenteritis \\
\hline 29 & 2011 & & 62 & M & $\begin{array}{l}\text { resection of the involved } \\
\text { mesentery }\end{array}$ & partial resection of the ileum & \\
\hline 30 & 2011 & {$[52]$} & 60 & M & open biopsy & steroid & accompanied by chylous ascites \\
\hline 31 & 2012 & {$[53]$} & 59 & $\mathrm{~F}$ & $\begin{array}{l}\text { resection of the involved } \\
\text { mesentery }\end{array}$ & $\begin{array}{l}\text { partial resection of the } \\
\text { jejunum }\end{array}$ & $\begin{array}{c}\text { caused by abberant pancreas in the } \\
\text { mesenterium }\end{array}$ \\
\hline 32 & 2012 & {$[54]$} & 52 & M & $\mathrm{CT}$ & steroid & onset under peritoneal dialysis \\
\hline 33 & & Our case & 28 & M & open biopsy & $\begin{array}{l}\text { steroid, colchicine and } \\
\text { azathioprine }\end{array}$ & $\begin{array}{l}\text { possibly accompanied by protein- } \\
\text { losing enteropahty }\end{array}$ \\
\hline
\end{tabular}

or surgical intervention was adequate to improve the patient's condition. However, three patients, including ours, were resistant to therapy, two of whom died (not including our patient). According to this review, Japanese patients with sclerosing mesenteritis involving the small bowel mesentery generally have characteristics similar to those of Western patients. The present patient appears to be rare in that the disease was refractory.

The precise etiology of sclerosing mesenteritis remains unknown. However, the disease appears to be caused by a nonspecific response to a wide variety of stimuli, including abdominal surgery or trauma $(1,2,14)$, autoimmunity (15-20), malignancy $(1,21,22)$, ischemic injury and infection (23). Other factors have also been reported, such as chronic inflammatory conditions, collagen vascular diseases (2) and IgG-4 related disease (24). In the present case, none of the associated conditions described above were identified.

A variety of clinical manifestations of sclerosing mesenteritis have been described, and several asymptomatic cases have been reported $(1,2,21)$. Many of these cases were diagnosed incidentally when the patients underwent radiologic procedures for other indications (21). As for symptomatic cases, the most common presenting manifestations are abdominal pain, nausea, vomiting, altered bowel habits, anorexia, body weight loss and palpable abdominal masses $(1,2,14)$. In the present case, both upper abdominal pain and a palpable abdominal mass were observed, and the area of abdominal pain completely accorded with the location of the palpable mass. There were no abnormalities, such as gastroduodenal ulcers, pancreatitis or gallbladder stones, that may have caused abdominal pain. Therefore, the patient's abdominal pain was strongly believed to have been caused by the sclerosing mesenteritis itself. Because the symptoms of sclerosing mesenteritis are nonspecific and varied, it is important to consider the possibility of this condition when examining patients with such symptoms.

Laboratory findings are not crucial for diagnosing sclerosing mesenteritis. Although an increased erythrocyte sedimentation rate (ESR) and C-reactive protein (CRP) level may be 
Table 3. Summary of the Cases that Received Medical Treatment Only

\begin{tabular}{ccccc}
\hline $\begin{array}{c}\text { Case } \\
\text { No. }\end{array}$ & Age & Sex & Medical Treatment & Treatment response \\
\hline 1 & 48 & M & gamma globulin & Responsive \\
2 & 53 & M & conservative & Responsive \\
3 & 50 & M & steroid & Responsive \\
5 & 31 & F & conservative & Responsive \\
6 & 65 & M & steroid & Responsive \\
7 & 33 & M & steroid & Responsive \\
8 & 89 & M & steroid & Responsive \\
9 & 41 & F & conservative & Responsive \\
11 & 69 & M & steroid & Responsive \\
12 & 67 & F & conservative & Responsive \\
13 & 77 & F & steroid & Responsive \\
15 & 74 & F & conservative & Responsive \\
16 & 79 & M & steroid & Responsive \\
19 & 62 & M & steroid & Responsive \\
20 & 39 & M & gamma globulin & Responsive \\
21 & 79 & M & steroid & Responsive \\
26 & 51 & M & conservative & Responsive \\
27 & 77 & M & conservative & None (Died) \\
30 & 60 & M & steroid & Responsive \\
32 & 52 & M & steroid & Responsive \\
33 & 28 & M & steroid, colchicine and azathioprine & None (Alive) \\
\hline
\end{tabular}

The case numbers are same as those in Table 2.

found in a minor proportion of patients, the laboratory findings in many patients are normal. In the present case, low levels of total protein, albumin and IgG were found, and hypoproteinemia likely induced the bilateral pretibial edema observed in our patient. Based on the endoscopic and histological findings of the jejunal mucosa, the above conditions were presumably caused by protein loss from the dilated lymphatic vessels of the jejunum. We speculate that the mesenteric mass disturbed the lymph flow in the ducts, inducing leakage of lymphatic fluid from the dilated lymphatic vessels as a secondary change.

Radiographic findings are essential for diagnostically evaluating sclerosing mesenteritis, with abdominal CT being the most sensitive imaging modality for diagnosis. The CT findings of the disease are varied, depending on the predominant tissue component (inflammatory phase or fibrotic phase) $(2,21)$. The most common finding is the presence of a soft tissue mass in the mesentery. Mass lesions are visualized as more heterogeneous in cases involving the inflammatory phase and more homogeneous in those involving the fibrotic phase. Calcification and cystic changes may also been seen, likely due to a necrotic process.

Additionally, the following two characteristic appearances have been proposed to be specific findings of sclerosing mesenteritis: 1) a "fat ring sign" and 2) the presence of a "tumoral pseudocapsule" $(15,25-27)$. The "fat ring sign" represents the preservation of fat nearest the mesenteric vessels $(26,28)$, while the presence of a "tumoral pseudocapsule" represents a band of soft tissue separating the uninvolved mesentery from the inflamed fat $(21,25)$. In the present case, a heterogeneous mass was found at the root of the small bowel mesentery and a "tumoral pseudocapsule" was detected, indicating that the patient had the typical CT findings of sclerosing mesenteritis.
The final and definitive diagnosis of sclerosing mesenteritis can be established based on a histologic examination of the mesentery. Histologically, the disease appears to progress in three consecutive stages: from mesenteric lipodystrophy to mesenteric panniculitis to retractile mesenteritis. Therefore, the histologic findings may reveal fat necrosis, chronic inflammation, fibrosis or a combination of any two or all three of these conditions $(1,2,29)$. In the present case, a histological examination of the thickened mesentery revealed infiltration of lymphocytes with adipocyte necrosis, indicating that the disease had progressed to the stage of mesenteric lipodystrophy or mesenteric panniculitis without the development of fibrosis.

There is no consensus regarding medical therapy for sclerosing mesenteritis. Asymptomatic cases can be managed without medication. As for symptomatic patients, the treatment is usually empiric and individualized. Some symptomatic patients have been reported to improve following treatment with corticosteroids $(2,30,31)$. In addition to corticosteroids, colchicine $(32,33)$, azathioprine $(34,35)$, cyclophosphamide (36), thalidomide (37) and tamoxifen $(2,38,39)$ have been reported to be beneficial. However, the regimen for managing sclerosing mesenteritis has not been established because the use of the above medications has only been reported in small case series. Performing surgical resection of the lesion is quite difficult due to the presence of associated vascular compromise and the extent of disease. Therefore, surgery should be attempted only in patients with severe complications, such as intestinal obstruction or perforation (40). In the present case, neither the patient's symptoms nor radiographic findings improved after treatment with corticosteroids, colchicine and azathioprine. However, surgical resection was not performed because the small bowel mesentery of the jejunum was shown to be widely involved on the CT scan and gross findings during laparotomy. If we had performed surgical resection of the involved lesion, quite a long segment of the jejunum would have needed to be removed. Such an operation could, with high probability, result in short bowel syndrome. Therefore, we did not perform short bowel resection. Fortunately, the patient's symptoms were relatively mild, and he continues to be observed at our hospital as an outpatient while receiving pain control.

In conclusion, we herein presented a rare Japanese case of refractory sclerosing mesenteritis involving the small bowel mesentery and reviewed the literature, including 32 recent Japanese case reports. According to our review, Japanese patients with sclerosing mesenteritis involving the small bowel mesentery generally have characteristics similar to those of Western patients. The present case appears to be rare in that the disease was refractory and possibly accompanied by protein-losing enteropathy. The etiology of sclerosing mesenteritis is not well understood, nor is the reason why the major portion of the mesentery frequently involved in such patients differs between races. Furthermore, differences between the small bowel mesentery type and large bowel mes- 
Table 4. Summary of the Cases Treated Surgically

\begin{tabular}{|c|c|c|c|c|c|}
\hline $\begin{array}{l}\text { Case } \\
\text { No. }\end{array}$ & Age & Sex & Main reasons for the operation & Operative procedure & $\begin{array}{c}\text { Clinical courses after the } \\
\text { operation }\end{array}$ \\
\hline 4 & 63 & $\mathrm{M}$ & To control the acute symptoms & duodeno-jejunostomy & Good \\
\hline 10 & 73 & M & Resistant to the conservative therapy & partial resection of the small bowel & Good \\
\hline 14 & 72 & M & ileus & jejunal-transeverse colostomy & Died \\
\hline 17 & 77 & $\mathrm{~F}$ & Resistant to the conservative therapy & $\begin{array}{c}\text { duodeno-jejunostomy, partial resection of } \\
\text { the small bowel }\end{array}$ & Good \\
\hline 18 & 37 & M & ileus & adhesiotomy & Good \\
\hline 22 & 79 & $\mathrm{~F}$ & To make a histological diagnosis & partial resection of the small bowel & Good \\
\hline 23 & 56 & M & Resistant to the conservative therapy & ileocecectomy & Good \\
\hline 24 & 58 & M & ileus & partial resection of the ileum & Good \\
\hline 25 & 75 & M & To make a histological diagnosis & partial resection of the ileum & Good \\
\hline 28 & 82 & M & To make a histological diagnosis & ileocecectomy & Good \\
\hline 29 & 62 & M & To make a histological diagnosis & partial resection of the ileum & Good \\
\hline 31 & 59 & $\mathrm{~F}$ & To control the acute symptoms & partial resection of the the jejunum & Good \\
\hline
\end{tabular}

The case numbers are same as those in Table 2.

entery type have not been clarified, and there is no standardized treatment for the disease. In particular, there is little information regarding Japanese cases involving the small bowel mesentery. The accumulation of additional case studies is required to understand this disease.

The authors state that they have no Conflict of Interest (COI).

\section{References}

1. Emory TS, Monihan JM, Carr NJ, Sobin LH. Sclerosing mesenteritis, mesenteric panniculitis and mesenteric lipodystrophy: a single entity? Am J Surg Pathol 21: 392-398, 1997.

2. Akram S, Pardi DS, Schaffner JA, Smyrk TC. Sclerosing mesenteritis: clinical features, treatment, and outcome in ninety-two patients. Clin Gastroenterol Hepatol 5: 589-596, 2007.

3. Asada Y, Kanda K, Ozeki K, Tanaka T, Mizuta Y, Kohno S. Two cases of mesenteric panniculitis. Nihon Shokakibyo Gakkai Zasshi (Journal of Japanese Society of Gastroenterology) 103: 13721376, 2006 (in Japanese, Abstract in English).

4. Nishiya D, Mikami T, Fukuda S, et al. A case of suspected mesenteric panniculitis with a large amount of chylous ascites. Nihon Shokakibyo Gakkai Zasshi (Journal of Japanese Society of Gastroenterology) 104: 1212-1217, 2007 (in Japanese, Abstract in English).

5. Nicholson JA, Smith D, Diab M, Scott MH. Mesenteric panniculitis in Merseyside: a case series and a review of the literature. Ann R Coll Surg Engl 92: W31-W34, 2010.

6. Zafar AM, Rauf MA, Chawla T, Khanda G. Mesenteric panniculitis with pedal edema in a 33-year-old Pakistani man: a case report and literature review. J Med Case Rep 2: 365, 2008.

7. Delgado Plasencia L, Rodriguez Ballester L, Lopez-Tomassetti Fernandez EM, Hernandez Morales A, Carrillo Pallares A, Hernandez Siverio N. Mesenteric panniculitis: experience in our center. Rev Esp Enferm Dig 99: 291-297, 2007.

8. Levy AD, Rimola J, Mehrotra AK, Sobin LH. From the archives of the AFIP: benign fibrous tumors and tumorlike lesions of the mesentery: radiologic-pathologic correlation. Radiographics 26 : 245-264, 2006.

9. Han SY, Koehler RE, Keller FS, Ho KJ, Zornes SL. Retractile mesenteritis involving the colon: pathologic and radiologic correlation (case report). AJR Am J Roentgenol 147: 268-270, 1986.

10. Popkharitov AI, Chomov GN. Mesenteric panniculitis of the sigmoid colon: a case report and review of the literature. J Med Case Rep 1: 108, 2007.
11. Mizutani K, Konishi J, Hayashida R, Nishimura Y, Yoshimori K, Shirouzu K. A case of mesenteric panniculitis associated with large amounts of chylous ascites. Nihon Rinsho Gekagakkai Zassi (J Jpn Surg Assoc) 64: 902-906, 2003 (in Japanese, Abstract in English).

12. Kida T, Suzuki K, Matsuyama $T$, et al. Sclerosing mesenteritis presenting as protein-losing enteropathy: a fatal case. Intern Med 50: 2845-2849, 2011.

13. Nomura Y, Naito Y, Eriguchi N, et al. A case of IgG4-related sclerosing mesenteritis. Pathol Res Pract 207: 518-521, 2011.

14. Durst AL, Freund H, Rosenmann E, Birnbaum D. Mesenteric panniculitis: review of the leterature and presentation of cases. Surgery 81: 203-211, 1977.

15. Horton KM, Lawler LP, Fishman EK. CT findings in sclerosing mesenteritis (panniculitis): spectrum of disease. Radiographics 23: 1561-1567, 2003.

16. Papadaki HA, Kouroumalis EA, Stefanaki K, et al. Retractile mesenteritis presenting as fever of unknown origin and autoimmune haemolytic anaemia. Digestion 61: 145-148, 2000.

17. Vidarsson B, Matthiasson P, Agnarsson BA, Onundarson PT. Mesenteric panniculitis presenting with autoimmune haemolytic anaemia. Acta Haematol 107: 35-37, 2002.

18. Vernace MA, Bellucci AG, Mossey RT, et al. Minimal change nephropathy associated with sclerosing mesenteritis. Nephron $\mathbf{7 3}$ : 473-476, 1996.

19. Dor AM, Kohler JL, Aubrespy P, Scheiner C, Pizzi M, Lebreuil G. Mesenteric panniculitis, an unusual initial stage of acute lupus erythematosus in a ten-year old girl. Arch Anat Cytol Pathol 30: 121-124, 1982 (in French, Abstract in English).

20. Sauvaget F, Piette JC, Galezowski N, et al. Relapsing polychondritis and mesenteric panniculitis: apropos of 2 cases. Rev Med Interne 14: 253-256, 1993.

21. Daskalogiannaki M, Voloudaki A, Prassopoulos P, et al. CT evaluation of mesenteric panniculitis: prevalence and associated diseases. AJR Am J Roentgenol 174: 427-431, 2000.

22. Goh J, Otridge B, Brady H, Breatnach E, Dervan P, MacMathuna P. Aggressive multiple myeloma presenting as mesenteric panniculitis. Am J Gastroenterol 96: 238-241, 2001.

23. Issa I, Baydoun H. Mesenteric panniculitis: various presentations and treatment regimens. World J Gastroenterol 15: 3827-3830, 2009.

24. Chen TS, Montgomery EA. Are tumefactive lesions classified as sclerosing mesenteritis a subset of IgG4-related sclerosing disorders? J Clin Pathol 61: 1093-1097, 2008.

25. Sabate JM, Torrubia S, Maideu J, Franquet T, Monill JM, Perez C. Sclerosing mesenteritis: imaging findings in 17 patients. AJR Am J Roentgenol 172: 625-629, 1999. 
26. Valls C. Fat-ring sign in sclerosing mesenteritis. AJR Am J Roentgenol 174: 259-260, 2000.

27. Okino Y, Kiyosue H, Mori H, et al. Root of the small-bowel mesentery: correlative anatomy and CT features of pathologic conditions. Radiographics 21: 1475-1490, 2001.

28. Wat SY, Harish S, Winterbottom A, Choudhary AK, Freeman AH. The CT appearances of sclerosing mesenteritis and associated diseases. Clin Radiol 61: 652-658, 2006.

29. Vettoretto N, Diana DR, Poiatti R, Matteucci A, Chioda C, Giovanetti M. Occasional finding of mesenteric lipodystrophy during laparoscopy: a difficult diagnosis. World J Gastroenterol 13: 53945396, 2007.

30. Kikiros CS, Edis AJ. Mesenteric panniculitis resulting in bowel obstruction: response to steroids. Aust N Z J Surg 59: 287-290, 1989.

31. Miyake H, Sano T, Kamiya J, et al. Successful steroid therapy for postoperative mesenteric panniculitis. Surgery 133: 118-119, 2003.

32. Iwanicki-Caron I, Savoye G, Legros JR, Savoye-Collet C, Herve S, Lerebours E. Successful management of symptoms of steroiddependent mesenteric panniculitis with colchicine. Dig Dis Sci 51: 1245-1249, 2006

33. Genereau T, Bellin MF, Wechsler B, et al. Demonstration of efficacy of combining corticosteroids and colchicine in two patients with idiopathic sclerosing mesenteritis. Dig Dis Sci 41: 684-688, 1996.

34. Tytgat GN, Roozendaal K, Winter W, Esseveld MR. Successful treatment of a patient with retractile mesenteritis with prednisone and azathioprine. Gastroenterology 79: 352-356, 1980.

35. Bala A, Coderre SP, Johnson DR, Nayak V. Treatment of sclerosing mesenteritis with corticosteroids and azathioprine. Can J Gastroenterol 15: 533-535, 2001.

36. Bush RW, Hammar SP Jr, Rudolph RH. Sclerosing mesenteritis. Response to cyclophosphamide. Arch Intern Med 146: 503-505, 1986.

37. Ginsburg PM, Ehrenpreis ED. A pilot study of thalidomide for patients with symptomatic mesenteric panniculitis. Aliment Pharmacol Ther 16: 2115-2122, 2002.

38. Mazure R, Fernandez Marty P, Niveloni S, et al. Successful treatment of retractile mesenteritis with oral progesterone. Gastroenterology 114: 1313-1317, 1998.

39. Venkataramani A, Behling CA, Lyche KD. Sclerosing mesenteritis: an unusual cause of abdominal pain in an HIV-positive patient. Am J Gastroenterol 92: 1059-1060, 1997.

40. Parra-Davila E, McKenney MG, Sleeman D, et al. Mesenteric panniculitis: case report and literature review. Am Surg 64: 768$771,1998$.

41. Kato N, Suzuki H, Tanaka J, et al. A case of mesenteric panniculitis with the onset of acute peritonitis, successful treatment with immunoglobulin. Nihon Shokakigeka Gakkai Zassi (Jpn Gastroenterol Surg) 33: 1525-1528, 2000 (in Japanese, Abstract in English).

42. Hyodo T, Kouno Y, Shibamoto K, et al. A case of mesenteric pan- niculitis that CT diagnosis was useful. Rinsho Hoshasen (Jpn J Clin Radiol) 46: 825-829, 2001 (in Japanese, Abstract in English).

43. Hiraguri M, Koike S, Kubota K, et al. A case of gastric cancer occurred obstruction of the afferent loop after a gastrectomy with mesenteric panniculitis. Nihon Rinsho Gekagakkai Zassi (J Jpn Surg Assoc) 63: 2449-2452, 2002 (in Japanese, Abstract in English).

44. Mizunuma K, Haruta Y, Shinhara R, et al. Low-dose steroid medication is effective for mesenteric panniculitis: A case report. Nihon Shokakigeka Gakkai Zassi (Jpn Gastroenterol Surg) 36: 15981602, 2003 (in Japanese, Abstract in English).

45. Uji Y, Nakae A, Mstui S, Shimode Y, Akami T, Tanaka T. A case of mesenteric panniculitis of the small intestine. Nihon Rinsho Gekagakkai Zassi (J Jpn Surg Assoc) 64: 2486-2489, 2003 (in Japanese, Abstract in English).

46. Yoshimoto Y, Shimizu R, Saeki T, et al. A case of recurrent mesenteric panniculitis with large amount of chylous ascites. Nihon Shokakigeka Gakkai Zassi (Jpn Gastroenterol Surg) 37: 697-701, 2004 (in Japanese, Abstract in English).

47. Hagiwara K, Hashizume M, Tsunoda H, Yoshida N, Kawaguchi T. A case of mesenteric panniculitis of the jejunum diagnosed and improved without operation. Nihon Rinsho Gekagakkai Zassi (J Jpn Surg Assoc) 66: 1194-1198, 2005 (in Japanese, Abstract in English).

48. Shimoji K, Oshiro J, Kinjo O, Kuniyoshi Y. A case of mesenteric panniculitis. Nihon Rinsho Gekagakkai Zassi (J Jpn Surg Assoc) 68: 452-456, 2007 (in Japanese, Abstract in English).

49. Ueda $S$, Minari $Y$, Ienaga $T$. Intestinal obstruction caused by severe omento-mesenteric panniculitis following rectal cancer surgery. Nihon Rinsho Gekagakkai Zassi (J Jpn Surg Assoc) 69: 2413-2417, 2008 (in Japanese, Abstract in English).

50. Kojima Y, Matsumoto H, Mikami Y, et al. A case of preoperatively undiagnosed retractile mesenteritis. Nihon Shokakigeka Gakkai Zassi (Jpn Gastroenterol Surg) 41: 318-323, 2008 (in Japanese, Abstract in English).

51. Shimoji K. A conservative case of mesenteric panniculitis. Nihon Hukubu Kyukyu Igakukai Zassi (J Abdom Emerg Med) 29: 763765, 2009 (in Japanese, Abstract in English).

52. Kubo S, Idani H, Asami S, et al. A case of mesenteric panniculitis with massive chylous ascites. Nihon Rinsho Gekagakkai Zassi (J Jpn Surg Assoc) 72: 801-805, 2011 (in Japanese, Abstract in English).

53. Iwasita $S$, Igarashi $T$, Matsushima $S$, et al. Panniculitis and fat necrosis derived from the ectopic pancreas of the jejunal mesentery. Rinsho Houshasen (Jpn J Clin Radiol) 57: 700-703, 2012 (in Japanese, Abstract in English).

54. Araki T, Murakami M, Sato M, Kanbe K, Tamura K, Miura H. Obstruction of dialysate drainage due to mesenteric panniculitis in a patient on peritoneal dialysis. Nihon Toseki Igakukai Zassi (J Jpn Soc Dial Ther) 45: 261-266, 2012 (in Japanese, Abstract in English).

(C) 2014 The Japanese Society of Internal Medicine http://www.naika.or.jp/imonline/index.html 